\title{
KONFORMITAS TEMAN SEBAYA DAN PERILAKU BULLYING DI SMP NEGERI 6 KARAWANG
}

\author{
Eka Lala Andriani ${ }^{1}$, Marhisar Simatupang ${ }^{2}$, Wina Lova Riza ${ }^{3}$ \\ Email:ps15.Ekaandriani@mhs.ubpkarawang.ac.id
}

Fakultas Psikologi Universitas Buana Perjuangan Karawang

\begin{abstract}
The problem in this research is the existence of bullying that occurred at SMPN 6 Karawang. Bullying behavior that suddenly occurs in deviance is caused by peer conformity. Researchers conducted a study that aims to determine the relationship between peer conformity with bullying behavior in students of SMPN 6 Karawang Barat. This study uses quantitative methods, measuring by distributing questionnaires. The subjects of this study were 188 respondents. In this study, the dependent variable peer conformity was used, and the independent variable was bullying behavior. The sampling used was cluster random sampling technique. The cluster random sampling technique is used to determine the sample if the object to be studied or the data source is very broad. Hypothesis testing obtained significance shows that the error rate is below 0.01, which means that the results of this study are accurate to $99 \%$ and a determinant coefficient of 0.289 means that the conformity variable affects the bullying variable by $28.9 \%$. So it can be concluded that there is a significant relationship between the peer conformity variable and bullying behavior.
\end{abstract}

Keyword: Peer conformity, bullying.

\begin{abstract}
Abstrak
Permasalah dalam penelitian ini adalah adanya tindakan bullying yang terjadi pada SMPN 6 Karawang. Perilaku bullying yang berdampak pada penyimpangan disebabkan oleh adanya konformitas teman sebaya. peneliti melakukan penelitian yang bertujuan untuk mengetahui hubungan antara konformitas teman sebaya dengan perilaku bullying pada siswa SMPN 6 Karawang barat. Penelitian ini menggunakan metode kuantitatif, mengukur dengan cara menyebar kuesioner. Subjek penelitian ini berjumlah 188 responden. Pada penelitian ini menggunakan variabel terikat konformitas teman sebaya, dan variabel bebas yaitu perilaku bullying. pengambilan sampel yang digunakan adalah teknik cluster random sampling. Teknik cluster random sampling digunakan untuk menentukan sampel bila obyek yang akan diteliti atau sumber data sangat luas. Uji hipotesis diperoleh signifikansi menunjukkan bahwa tingkat error berada dibawah 0.01 yang artinya hasil penelitian ini akurat sampai dengan 99\% dan koefisien determinan sebesar 0,289 mengandung arti bahwa variabel konformitas mempengaruhi variabel bullying sebesar 28.9\%. Maka dapat
\end{abstract}


disimpulkan bahwa ada hubungan secara signifikan antara variabel konformitas teman sebaya dengan perilaku bullying.

Kata Kunci: Konformitas teman sebaya, perilaku bullying.

\section{PENDAHULUAN}

Perilaku kekerasan (bullying) yang dilakukan oleh remaja baik di sekolah maupun di luar sekolah semakin banyak sering terdengar dan menghiasi media cetak maupun media elektronik. Tidak sedikit remaja yang telah menjadi korban perilaku kekerasan (bullying). Kemampuan remaja untuk dapat mengendalikan diri merupakan hal yang sangat penting dilakukan, karena untuk mengurangi terjadinya perilaku yang menyimpang, dimana perilaku menyimpang itu seperti perilaku bullying, dan kenakalan yang lain saat ini marak dilakukan oleh remaja.

Menurut KPAI kasus kekerasan (bullying) di sekolah menduduki peringkat teratas di sektor pendidikan. Berdasarkan hasil pemantauan Komisi Perlindungan Anak Indonesia (KPAI) merilis hasil pengawasan dan pengaduan kekerasan (bullying) di lembaga pendidikan. Sejak bulan Januari hingga Oktober 2019, tercatat 127 kasus yang terdiri dari kekerasan fisik, psikis, dan seksual (Bunga, 2019). Hal tersebut menguatkan bahwa kasus kekerasan bullying masih banyak terjadi di sekolah-sekolah yang berada di Indonesia.

Menurut Santrock (2008) remaja adalah masa perkembangan transisi antara masa anak-anak dan masa dewasa yang mencakup perubahan biologis, kognitif, dan sosial emosional. Saat ini jumlah remaja di Indonesia terus meningkat dari data yang ada, Hasil Survei Penduduk Antar Sensus 2015 menunjukkan bahwa penduduk usia 15-24 tahun mencapai 42.061,2 juta atau sebesar 16,5 persen dari total penduduk Indonesia (Lembaga Demografi, 2017). Jumlah remaja yang cukup tinggi perlu menjadi perhatian agar tumbuh dan berkembang dengan perkembangan dan perubahan yang baik.

Perilaku bullying tersebut dapat memberikan dampak negatif, baik bagi korban maupun pelaku. Dampak dari bullying fisik yaitu akan mengalami luka memar, sakit kepala, luka tergores dan sakit fisik lainnya. Dari beberapa kasus yang sudah terjadi bahkan sampai ada yang mengalami kematian. Dampak psikologisnya yaitu, menurunnya kesejahteraan psikologis, semakin buruknya penyesuaian sosial, dendam, kesal, takut, malu, sedih, terancam, cemas, dan bahkan keinginan korban untuk bunuh diri (Hamzah, 2015) . Dalam kesehariaannya siswa yang khususnya pada masa remaja menganggap sahabatnya lebih penting daripada keluarganya sendiri. Selain itu remaja juga lebih banyak menghabiskan waktunya dengan sahabat mereka dibandingkan keluarganya (Murtiyanti dalam Muhlisin, 2016). Konformitas teman sebaya secara operasional diukur dengan menggunakan skala informasi sosial, sosial normatif dan membenarkan konformitasyang dikemukakan oleh Taylor (2009). Sebagian besar perilaku bullying yaitu dilakukan secara bersama-sama dalam setting kelompok, terbukti dengan adanya berbagai kasus bullying yang terjadi dengan pelaku berjumlah banyak dalam lingkup kelompok teman sebaya.Yang menjadi titik fokus remaja yaitu diakui atau diterimanya di dalam suatu kelompok dan dari situlah remaja akan berinteraksi di dalam lingkungan sosial atau 
kelompoknya itu. Oleh karena itulah remaja akan melakukan cara apapun agar keberadaannya di akui di suatu kelompok. Proses ini lah yang di namakan dengan konformitas.

\section{LANDASAN TEORI}

\section{Konformitas Teman Sebaya}

Menurut Dewi (2015) Kegiatan individu melakukan perilaku bullying yang disebabkan modelling kelompok teman sebaya ini dapat dikatakan individu tersebut melakukan konformitas teman sebaya. Sejalan dengan itu menurut Baron, dkk., (dalam Hidayat, 2016) konformitas adalah penyesuaian perilaku untuk mengikuti norma kelompok acuan, serta menerima ide atau aturan-aturan kelompok yang mengatur cara individu berperilaku. Konformitas adalah perubahan perilaku untuk menyesuaikan diri dengan kelompok yang di anut. Konformitas juga memiliki banyak bentuk dan mempengaruhi banyak aspek kehidupan seseorang (King, 2010).

Menurut Taylor, dkk (2009) dalam bukunya mengemukakan bahwa adanya aspek-aspek dalam konformitas yaitu: a). Pengaruh sosial normatif: keinginan akan disukai dan takut akan penolakan, b). Pengaruh informasional sosial: keinginan untuk merasa benar, c). Membenarkan konformitas: konsekuensi kognitif dari pengikut kelompok.

Faktor-faktor yang mempengaruhi konformitas teman sebaya Menurut Baron, dkk., (2012) yaitu:

\section{Kohesivitas}

Salah satu faktor yang sangat mempengaruhi kecenderungan kita untuk menyesuaikan diri (melakukan konformitas sosial adalah kohesivitas atau kekompakan kelompok.

\section{Ukuran kelompok}

Faktor lainnya yang menghasilkan efek sama dengan kehesivitas dalam mempengaruhi perilaku orang lain adalah ukuran kelompok. Hasil-hasil penelitian terbaru mengonfirmasi hasil-hasil penelitian terdahulu yang mengatakan bahwa semakin besar ukuran kelompok maka, semakin besar pula tekanan yang didapatkan seseorang untuk menyesuaikan diri

\section{Norma sosial}

Pengaruh norma sosial tidak kalah besar. Norma sosial dapat dibedakan menjadi dua, yaitu norma deskriptif dan norma injungtif. Norma deskriptif merupakan norma yang hanya mendeskripsikan (mewartakan) apa yang sebagian orang lakukan pada situasi tertentu. Norma ini dapat mempengaruhi tingkah laku dengan cara memberi tahu kita apa yang umumnya dianggap efektif atau adaptif pada situasi tersebut.

\section{Perilaku Bullying}

Olweus (Ponny, 2008) menyatakan bahwa bullying merupakan tindakan agresi proaktif. Tidakan agresi proaktif merupakan tindakan yang sengaja dilakukan oleh 
seseorang atau kelompok sebagai motivasi awal atau hukuman pada korbannya untuk mendapatkan balasan. Menurut Novan (2012) bullying adalah perilaku negatif yang mengakibatkan seseorang dalam keadaan tidak nyaman atau terluka dan biasanya terjadi berulang-ulang. Murphy (2009) memberikan pandangan terhadap perilaku bullying yaitu keinginan untuk menyakiti seseorang, yang sebagian besar melibatkan kekuatan yang tidak seimbang.

Dari beberapa definisi di atas dapat disimpulkan bahwa definisi dari bullying adalah perilaku yang dikenal dengan istilah pengucilan hingga tindakan yang merugikan orang lain secara sadar dan dilakukan berulang-ulang.

Terdapat aspek-aspek bullying menurut Amini (2008) antara lain:

1. Bullying fisik, yaitu jenis bullying yang kasat mata, karena terjadi sentuhan fisik antara pelaku bullying dan korbannya. Indikatornya yaitu melempar, menjegal, merampas atau mengambil uang secara paksa.

2. Bullying verbal, merupakan jenis bullying yang terdeteksi bisa tertangkap indra pendengaran kita. Indikatornya yaitu memaki, mempermalukan depan umum.

3. Bullying mental atau psikologis. Indikatornya yaitu memandang sinis, mengucilkan seseorang, dan melakukan terror.

\section{METODE PENELITIAN}

Dalam penelitian ini menggunakan metode penelitian jenis kuantitatif dengan menggunakan teknik pengambilan sampel yaitu cluster random sampling (probability) digunakan untuk menentukan sampel bila obyek yang akan diteliti atau sumber data sangat luas. Siswa-siswi kelas 8 SMPN 6 Karawang berjumlah 400 siswa Dalam penentuan jumlah sampel dari populasi peneliti menggunakan tabel penentuan jumlah sampel yang dikembangkan dari Isaac dan Michael dengan tingkat kesalahan 5\%. berdasarkan tabel Isaac dan Michael dengan tingkat kesalahan 5\% dapat diketahui bahwa sampel dari populasi 400 siswa berjumlah 186 siswa.

Alat ukur penelitian menggunakan skala konformitas teman sebaya yang diadaptasi dari Taylor, dkk (2009) dan skala perilaku bullying yang diadaptasi dari Amini (2008).

\section{HASIL DAN PEMBAHASAN}

Tabel 1. Uji Normalitas

Tests of Normality

\begin{tabular}{lr|r|r|r|r|r} 
& \multicolumn{4}{c}{ Kolmogorov-Smirnov } & \multicolumn{3}{c}{ Shapiro-Wilk } \\
& Statistic & \multicolumn{1}{c}{ Df } & \multicolumn{1}{c}{ Sig. } & Statistic & \multicolumn{1}{c}{ Df } & \multicolumn{1}{c}{ Sig. } \\
\hline TKON & .054 & 188 & $.200^{*}$ & .994 & 188 & .627 \\
\hline TBULL & .026 & 188 & .054 & .973 & 188 & .051 \\
\hline
\end{tabular}

*. This is a lower bound of the true significance.

a. Lilliefors Significance Correction

Dari tabel di atas dapat diketahui bahwa nilai uji normalitas berdasarkan teknik Kolmogorov-Smirnov dari variabel konformitas adalah sebesar 0,200 > 0,05 
maka dapat dikatakan data berdistribusi normal, sementara dari variabel bullying sebesar 0,054 > 0,05 maka dapat dikatakan data berdistribusi normal.

Tabel 2. Uji Linearitas

Anova Table

\begin{tabular}{|c|c|c|c|c|c|c|c|}
\hline & & & $\begin{array}{l}\text { Sum of } \\
\text { Squares }\end{array}$ & $\mathrm{df}$ & $\begin{array}{l}\text { Mean } \\
\text { Square }\end{array}$ & $\mathrm{F}$ & Sig. \\
\hline \multirow{5}{*}{$\begin{array}{l}\text { Total_Bullying * } \\
\text { Total_Konformitas }\end{array}$} & & (Combined) & 11627.657 & 55 & 211.412 & 2.106 & .000 \\
\hline & $\begin{array}{l}\text { Between } \\
\text { Groups }\end{array}$ & Linearity & 7412.013 & 1 & 7412.013 & 73.833 & .000 \\
\hline & & \multicolumn{2}{|c|}{$\begin{array}{l}\text { Deviation from } \\
\text { Linearity }\end{array}$} & 54 & 78.067 & .778 & .852 \\
\hline & \multicolumn{2}{|c|}{ Within Groups } & 13251.295 & 132 & 100.389 & & \\
\hline & \multicolumn{2}{|l|}{ Total } & 24878.952 & 187 & & & \\
\hline
\end{tabular}

Berdasarkan nilai signifikansi dari tabel di atas diperoleh nilai Deviation from Linearity sebesar 0,852 >0,05. Maka dapat disimpulkan bahwa ada hubungan linear secara signifikan antara variabel konformitas dengan bullying.

Tabel 3. Uji Korelasi

\section{Correlations}

\begin{tabular}{llr|r} 
& \multicolumn{2}{c}{ TKON } & \multicolumn{1}{c}{ TBULL } \\
\hline \multirow{2}{*}{ TKON } & \multicolumn{1}{l}{ Pearson Correlation } & 1 & $.537^{* *}$ \\
\cline { 2 - 4 } & Sig. (2-tailed) & 188 & .000 \\
\cline { 2 - 4 } & $\mathrm{N}$ & $.537^{* *}$ & 188 \\
\hline \multirow{2}{*}{ TBULL } & Pearson Correlation & .000 & 1 \\
\cline { 2 - 4 } & Sig. (2-tailed) & 188 & 188 \\
\cline { 2 - 4 } & $\mathrm{N}$ & & \\
\hline **. Correlation & is significant at the 0.01 level (2-tailed).
\end{tabular}

Terdapat korelasi positif antara konformitas dengan bullying pada siswa SMPN6. Korelasi positif menandakan hubungan yang saling menguatkan, dengan kata lain semakin tinggi tingkat konformitas, semakin tinggi pula tingkat bullying pada responden yang dilibatkan dalam penelitian ini. Nilai siginifikansi menunjukkan bahwa tingkat error berada dibawah 0.01 yang artinya hasil penelitian ini akurat sampai dengan $99 \%$. 
Tabel 4. Kategorisasi Konformitas

Konformitas

\begin{tabular}{llr|r|r|r} 
& & & & \multicolumn{2}{c}{$\begin{array}{c}\text { Cumulative } \\
\text { Percent }\end{array}$} \\
\hline Valid & Frequency & Percent & Valid Percent & 4.3 \\
\cline { 2 - 6 } & sangat tinggi & 8 & 4.3 & 4.3 & 26.6 \\
\cline { 2 - 6 } & Tinggi & 42 & 22.3 & 22.3 & 96.8 \\
\cline { 2 - 6 } & Sedang & 132 & 70.2 & 70.2 & 100.0 \\
\cline { 2 - 6 } & Rendah & 6 & 3.2 & 3.2 & \\
\cline { 2 - 6 } & Total & 188 & 100.0 & 100.0 & \\
\hline
\end{tabular}

Dari tabel di atas dapat diketahui bahwa konformitas pada siswa SMPN 6 Karawang lebih banyak berada pada taraf sedang dengan total persentase 70,2\% dengan jumlah responden sebanyak 132 orang. Sementara taraf terendah dengan total persentase sebesar 3,2\% dengan jumlah responden sebanyak 6 orang.

Tabel 5. Kategorisasi Bullying

Frequency Percent Valid Percent Cumulative Percent

\begin{tabular}{ccc|c|c|c}
\hline & .00 & 1 & .5 & .5 & .5 \\
\cline { 2 - 6 } & Sangat tinggi & 4 & 2.1 & 2.1 & 2.7 \\
\cline { 2 - 6 } Valid & Tinggi & 59 & 31.4 & 31.4 & 34.0 \\
\cline { 2 - 6 } & Sedang & 121 & 64.4 & 64.4 & 98.4 \\
\hline & Rendah & 3 & 1.6 & 1.6 & 100.0 \\
\hline
\end{tabular}

Dari tabel di atas dapat diketahui bahwa bullying pada siswa SMPN 6 Karawang lebih banyak berada pada taraf sedang dengan total persentase $64,4 \%$ dengan jumlah responden sebanyak 121 orang. Sementara taraf terendah dengan total persentase sebesar 1,6\% dengan jumlah responden sebanyak 3 orang.

Tabel 6. Crosstabulation Konformitas

Konformitas Jenis Kelamin Crosstabulation

\begin{tabular}{llr|r|r}
\multicolumn{4}{c}{ Laki-laki } & \multicolumn{2}{c}{ Perempuan } & \\
\hline KO & sangat tinggi & 2 & 6 & 8 \\
\cline { 2 - 5 } $\mathrm{N}$ & Tinggi & 16 & 26 & 42 \\
\cline { 2 - 5 } & Sedang & 57 & 75 & 132 \\
\cline { 2 - 5 } & Rendah & 3 & 3 & 6 \\
\hline & Total & 78 & 110 & 188 \\
\hline
\end{tabular}

Dari 188 subjek yang diteliti terdapat 2 orang laki-laki dan 6 orang perempuan dengan kategori konformitas sangat tinggi, 16 orang laki-laki dan 26 orang perempuan dengan kategori konformitastinggi, 57 orang laki-laki dan 75 orang perempuan dengan kategori konformitas sedang dan 3 orang laki-laki dan perempuan dengan kategorisasi konformitas rendah. 
Tabel 7. Crosstabulation Bullying

Jenis Kelamin Crosstabulation

\begin{tabular}{|c|c|c|c|c|}
\hline \multirow{2}{*}{ BULL } & \multicolumn{2}{|c|}{ Laki-laki } & Perempuan & \multirow[b]{2}{*}{1} \\
\hline & .00 & 1 & 0 & \\
\hline & 1.00 & 2 & 2 & 4 \\
\hline & 2.00 & 21 & 38 & 59 \\
\hline & 3.00 & 52 & 69 & 121 \\
\hline & 4.00 & 2 & 1 & 3 \\
\hline Total & & 78 & 110 & 188 \\
\hline
\end{tabular}

Dari 188 subjek yang diteliti terdapat 1 orang laki-laki dengan kategori bullying sangat tinggi, 2 orang laki-laki dan 2 orang perempuan dengan kategori bullying tinggi, 21 orang laki-laki dan 38 orang perempuan dengan kategori bullying sedang, 52 orang laki-laki dan 69 perempuan dengan kategorisasi bullying rendah dan 2 orang laki-laki dan 1 perempuan dengan kategorisasi bullying sangat rendah.

\section{KESIMPULAN}

Berdasarkan analisis data yang sudah dilakukan, maka dapat disimpulkan beberapa hal sebagai berikut:

Berbagai kasus bullying yang banyak dijumpai dilakukan dalam sebuah kelompok, lebih tepatnya kelompok teman sebaya atau biasa yang di sebut dengan kelompokmelakukan tindakan bullying maka individu tersebut secara tidak langsung akan memperhatikan perilaku bullying yang dilakukan kelompok tersebut. Ketika remaja melihat teman sebayanya melakukan hal yang sama seperti bullying maka mereka akan mungkin melakukan hal yang sama seperti yang dilakukan teman sebayanya dengan alasan menghindari penolakan.

Oleh karena itu dari penelitian ini dapat disimpulkan terdapat korelasi positif antara konformitas teman sebaya dengan perilaku bullying pada siswa SMPN 6 Karawang. Korelasi positif menandakan hubungan yang saling menguatkan, dengan kata lain semakin tinggi tingkat konformitas, semakin tinggi pula tingkat bullying pada responden yang dilibatkan dalam penelitian ini. Nilai siginifikansi menunjukkan bahwa tingkat error berada dibawah 0.01 yang artinya hasil penelitian ini akurat sampai dengan 99\%. Oleh karena itu terdapat hubungan antara konformitas teman sebaya dengan perilaku bullying.

\section{REFERENSI}

Amini, S. (Yayasan S. J. (2008). Bullying (Mengatasi Kekerasan Di Sekolah Dan Lingkungan). Jakarta: Grasindo.

Bunga, H. (2019). KPAI: Kekerasan di Dunia Pendidikan Mencapai 127 Kasus. Tempo. Retrieved from https://nasional.tempo.co/read/1266367/kpai-kekerasandi-dunia-pendidikan-mencapai-127-kasus

Cintia, D. K. (2015). Pengaruh konformitas teman sebaya terhadap perilaku bullying pada siswa. Fakultas Ilmu Pendidikan. Yogyakarta: Universitas Negeri Yogyakarta. 
Hamzah. (2015). Hubungan konformitas teman sebaya dengan perikalu bullying siswa di SMPN 2 Bantul. Yogyakarta: Sekolah Tinggi Ilmu Keperawatan.

Jahja,Y. (2011). Psikologi perkembangan. Jakarta: Kencana Prenada Media Grup.

Komaruddin, H., \& Khoiruddin. B. (2016). Psikologi Sosial. Jakarta: Erlangga.

King, L. A. (2010). Psikologi Umum (Sebuah Pandangan Apresiatif. Jakarta: Salemba Humanika.

Mintarsih, A.S., (2015) Hubungan antara perilaku prososialdengan kesejahteraan psikologis (psychological well-being) pada siswa kelas XI Di SMK Muhamadiyah 2 Yogyakarta. Skripsi.

Muhlisin, Z. (2016). Hubungan Pola Asuh Orang Tua Dengan Perilaku Kenakalan Remaja Di SMK Negri 1 Temon Kulon Progo D.I Yogyakarta. Stikes Jendral Ahmad Yani Yogyakarta.

Murphy, M.M., B. (2009). Dealing With Bullying. New York: Chealsea House.

Novan, A. . (2012). Save Our Children From School Bullying. Yogyakarta: Ar-Ruzz Media.

Ponny, R. A. (2008). Meredam Bullying: 3 Cara Efektif Menanggulangi Kekerasan Pada Anak. Jakarta: Garsindo.

Santrock, J. . (2008). Life Span Development Perkembangan Masa Hidup (13th ed.). Jakarta: Erlangga.

Taylor, S. E. P. Letitia, A. (2009). Psikologi Sosial (12th ed.). Jakarta: Kencana Predia Media Grup.

Yusuf, H.,\&Fahrudin, A. (2012). Perilaku bullying: Asesmen multidimensi dan intervensi sosial. Jurnal Psikologi Undip.

Umi, K.,\& M. Jauhar. (2014). Pengantar Psikologi Sosial. Jakarta: Prestasi Pustaka 